Central European Journal of Energetic Materials, 2016, 13(1), 53-71

ISSN 1733-7178

e-ISSN 2353-1843

\title{
Preparation of Nano Aluminium Powder (NAP) using a Thermal Plasma: Process Development and Characterization
}

Arti PANT ${ }^{1}$, Tanay $\mathrm{SETH}^{2}$, Varsha B. RAUT ${ }^{2}$, Vandana Prakash GAJBHIYE ${ }^{1}$, Shireeshkumar Pralhad NEWALE ${ }^{1}$, Amiya Kumar NANDI ${ }^{1}$, Hima PRASANTH ${ }^{1}$, Raj Kishore PANDEY ${ }^{1^{*}}$

${ }^{1}$ High Energy Materials Research Laboratory, Sutarwadi, Pune-411021, India

${ }^{2}$ Centre for Materials for Electronics Technology, Panchavati, Off Pashan Road, Pune-411008, India

*E-mail: rkpandey@hemrl.drdo.in

\begin{abstract}
A bottom up approach for the preparation of Nano Aluminium Powder (NAP) using a Transferred Arc Thermal Plasma Reactor (TAPR) is described. The aluminium block is subjected to evaporation by the application of a thermal plasma. The aluminium vapour produced is rapidly quenched to room temperature resulting in crystallization of the aluminium vapour in nano-particulate form. Various process parameters, such as the plasma torch power, reactor pressure and plasma gas composition were optimized. This paper also describes the characterization of NAP by analytical methods, for the estimation of the Active Aluminium Content (AAC), Total Aluminium Content (TAC), XRD, bulk density, BET surface area, HR-TEM etc. The results are compared with those for samples prepared in other thermal plasma reactors, such as the DC Arc Plasma Reactor (DCAPR) and the RF Induction Thermal Plasma Reactor (RFITPR), and for commercially available NAP samples (ALEX, prepared by the EEW technique).
\end{abstract}

Keywords: nano aluminium, thermal plasma, DC arc plasma, RF induction plasma, aluminium content, BET surface area, HR-TEM 


\section{Introduction}

Micron sized aluminium powder is one of the most widely used ingredients in explosive, propellant and pyrotechnic formulations. However, its full potential has not been exploited because of the incomplete combustion of $\mathrm{Al}$ and its extensive oxidation prior to combustion. This problem is somewhat mitigated with the use of NAP and the current research reveals that addition of NAP to composite propellants results in improvements in the burn rate and specific impulse (Isp), as well as in high explosive formulations to enhance the detonation properties and the underwater performance [1-12]. Various techniques are used to prepare NAP and these are divided into high temperature and low temperature processes. The high temperature techniques include gas evaporation [13-16], plasma chemical synthesis [17-22], laser ablation [23], arc discharge [24-26], electro-explosion [27-30], and ion implantation [31], whereas the low temperature techniques include solution methods [32-38] and mechanical attrition (ball milling) [39-40]. However, producing bulk NAP continues to be a technical challenge. Two different vapour condensation methodologies, viz. Electrical Explosion of Wire (EEW) and thermal plasma have been reported for bulk production of NAP. The thermal plasma route has inherent advantages such as a high production rate and control of the particle size (monodispersity).

We have developed a methodology for the preparation of NAP using a Transferred Arc Plasma Reactor (TAPR). It is a bottom up approach where an aluminium block is subjected to evaporation by the application of a thermal plasma. The aluminium vapour produced is rapidly quenched to room temperature resulting in the crystallization of aluminium particles in nano-particulate form. Various process parameters, such as plasma torch power, reactor pressure and plasma gas composition, were optimized for the process. This paper also describes the characterization of NAPs prepared by the TAPR method, by purity analysis, bulk density, surface area, XRD, HRTEM etc. These results are compared with NAP prepared by other thermal plasma reactors, such as the DC Arc Plasma Reactor (DCAPR) and the RF Induction Thermal Plasma Reactor (RFITPR), and with commercially available NAP samples (ALEX, prepared by the EEW technique).

\section{Experimental}

\subsection{Preparation of NAP by a thermal plasma}

Plasma is comprised of partially ionized gases at very high temperatures (5000$20,000 \mathrm{~K}$ ), and contains ions (positive and negative), electrons, molecules and 
neutral species. A plasma can deliver the energy necessary to cause evaporation of any solid, and also initiate chemical reactions. A Transferred Arc Thermal Plasma Reactor (TAPR) (make: TEKNA Inc. Canada) was used for the preparation of NAP (Figure 1).

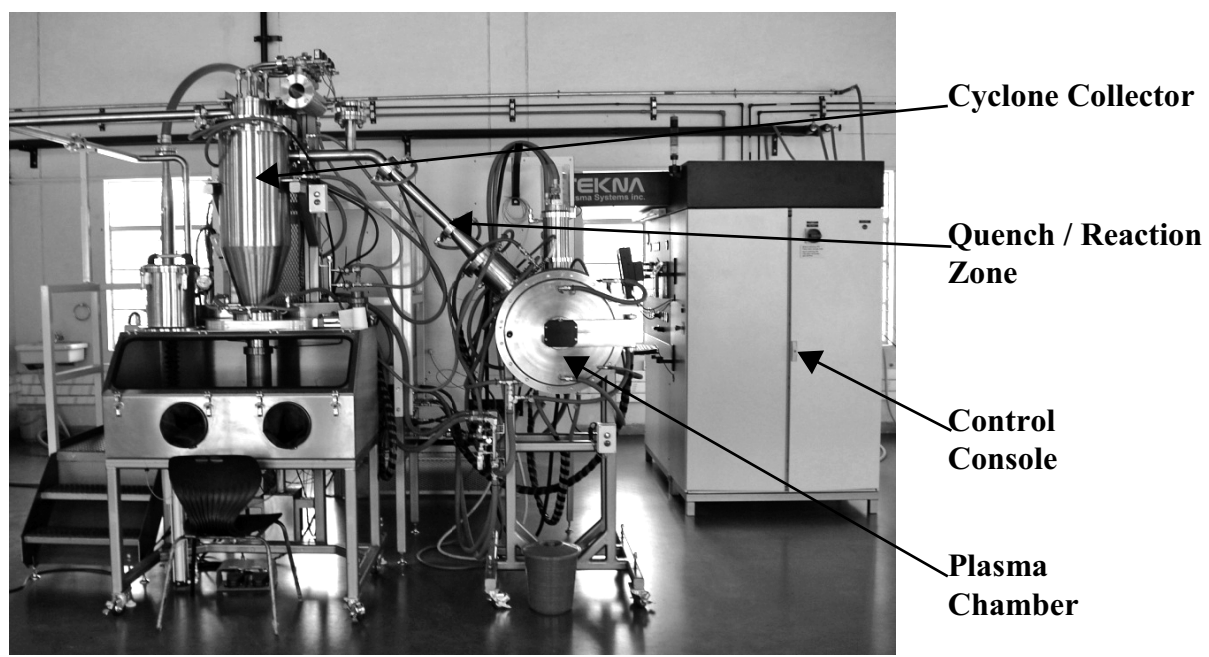

Figure 1. TAPR system used for the preparation of NAP samples.

A TAPR assembly consists of the following: the power supply, plasma torch and displacement system, cooling system, vacuum unit and pressure control system, plasma chamber, reactor chamber/quench sections and powder collection system. The system has a bank of two DC power supplies capable of giving a combined power of $30 \mathrm{~kW}$ (max.). A liquid ring vacuum pump was used to evacuate the system to a base pressure of $10^{-1}$ torr. The plasma torch gave currents up to $500 \mathrm{~A}$ in the transferred arc mode. A high temperature (up to $10,000 \mathrm{~K}$ ) was realised during the generation of the thermal plasma and hence very intense cooling of the exposed parts of the system was applied in order to protect them from the high heat flux. The TAPR system was equipped with deionised (DI) water circulation in the console, which provided the necessary cooling for the reactor, plasma torch and the electrode. The temperature of the DI water was kept at $\sim 15-20^{\circ} \mathrm{C}$. Aluminium blocks ( $\sim 99 \%$ pure) in the graphite crucible were used as the anode. The arc was generated using argon as a plasma gas. The argon plasma from the torch was allowed to impinge on the metal anode and subsequently transferred its heat to the target; this resulted in the vaporization of the aluminium (m.p. of aluminium $660^{\circ} \mathrm{C}$ ) in the evaporator/reactor chamber. The resulting aluminium vapour was subsequently subjected to rapid cooling via 
three quenching zones (Q-1, Q-2 and Q-3). NAP was formed due to the rapid homogeneous nucleation and quenching, resulting in the formation of very fine aluminium powder. After the reaction and quench zones, NAP passed through the cyclone collector and was collected at the bottom of the collector. NAP was collected in the canister under a controlled atmosphere.

\subsection{Analysis and characterization of NAPs}

\subsubsection{Reagents and NAP samples}

All of the reagents, such as cerium(IV) sulfate(VI), Mohr's salt [( $\left.\left(\mathrm{NH}_{4}\right)_{2} \mathrm{Fe}\left(\mathrm{SO}_{4}\right)_{2} \cdot 6 \mathrm{H}_{2} \mathrm{O}\right]$, conc. sulfuric acid, potassium dichromate, diphenylamine (indicator), phosphoric acid, ferroin (indicator), EDTA, zinc sulfate $\left[\mathrm{ZnSO}_{4} \cdot 7 \mathrm{H}_{2} \mathrm{O}\right]$, sodium acetate trihydrate, $\left[\mathrm{CH}_{3} \mathrm{COONa} \cdot 3 \mathrm{H}_{2} \mathrm{O}\right]$, conc. hydrochloric acid, sodium salt of xylenol orange etc. were of analytical grade. All solutions were prepared in distilled water.

This laboratory has also assessed NAP samples prepared by other methods, such as DC Arc Plasma Reactor (DCAPR), Radio Frequency Induction Plasma Reactor (RFIPR), and Electrical Explosion of Wire (EEW; ALEX powder).

\subsubsection{Characterization by instrumental methods}

The bulk density was measured by the conventional method using tap densitometer equipment. An accurately weighed NAP sample ( $\sim 8)$ was taken in a glass measuring cylinder $(50 \mathrm{~mL})$. The material was tapped using the above mentioned equipment to realize a constant value of the minimum volume required for the solid material. It took $\sim 40$ strokes to realize the minimum volume. The bulk density (BD) was calculated as follows:

$$
\mathrm{BD}=\mathrm{m} / \mathrm{V}
$$

where: $\mathrm{m}$ - mass of the powder taken for testing, $\mathrm{g}$, and $\mathrm{V}$ - volume occupied by the powder in the measuring cylinder, $\mathrm{cm}^{3}$.

The powder X-ray diffraction (XRD) of the NAP samples was measured in an X-ray Diffractometer (X'Pert PRO Panalytical and Bruker D8 advance) with a $\mathrm{Cu} \mathrm{K} \alpha$ source at a measurement angle range $2 \theta=20-70^{\circ}$. The surface area was measured by nitrogen adsorption using a Gemini VII 2390t surface area analyzer (Micromeritics, USA). The sample $(0.2 \mathrm{~g})$ was activated by heating at $250^{\circ} \mathrm{C}$ for $6 \mathrm{~h}$ under $\mathrm{N}_{2}$ gas purging. High Resolution Transmission Electron Microscopy (HRTEM) images were taken with a TECHNAI F-30 (FEI) instrument with a $300 \mathrm{kV}$ Field Emission Gun (FEG). The NAP sample was dispersed in hexane with the help of sonication. The dispersed mixture was mounted on a TEM grid. 
The solvent was evaporated by drying in an oven.

\subsection{Analytical method for the estimation of Active Aluminium Content (AAC)}

An accurately weighed NAP sample (50-60 mg) was transferred to a $250 \mathrm{~mL}$ conical flask and $0.2 \mathrm{~N}$ cerium(IV) sulfate(VI) solution $(50 \mathrm{~mL})$ was added to it. The powder was dissolved in the cerium(IV) sulfate(VI) solution by occasional swirling and by applying heat using a hot plate for $30 \mathrm{~min}$. The solution was cooled to room temperature and ferroin indicator (1-2 drops) were then added. This solution was titrated against standard Mohr's salt solution. The colour change at the end point was dark yellow to orange. The burette reading $\left(\mathrm{V}_{\mathrm{s}}\right)$ was noted. Similarly, a blank titration was carried out without aluminium powder and the blank reading $\left(\mathrm{V}_{\mathrm{b}}\right)$ was noted.

$$
\text { Calculation: \% } A A C=\left(V_{\mathrm{b}}-V_{s}\right) \times N \times M \times \frac{0.1}{m}
$$

where: $M=8.993 \mathrm{~g}$ (equivalent mass of aluminium); $m$ - mass of Al in sample, $\mathrm{g}$; $V_{b}$ - blank burette reading without sample solution; $V_{S}$ - burette reading with sample solution, $\mathrm{mL} ; N$ - normality of Mohr's salt.

\subsection{Analytical method for the estimation of Total Aluminium Content (TAC)}

\subsubsection{Preparation of aluminium stock solution}

An accurately weighed NAP sample $(70 \mathrm{mg})$ was transferred to a clean $50 \mathrm{~mL}$ beaker. Concentrated hydrochloric acid $(5 \mathrm{~mL})$ was added and the mixture was boiled for about $20 \mathrm{~min}$ on a hot plate. If any powder remained on the walls, it was washed down with distilled water $(25 \mathrm{~mL})$ and boiled again. The beaker was cooled to near room temperature. This solution was then made up to $250 \mathrm{~mL}$ in a volumetric flask with distilled water.

\subsubsection{Formation of the Al-EDTA complex and back titration of the excess EDTA with standard zinc sulfate solution}

The aluminium stock solution $(10.00 \mathrm{~mL})$ was added to a $125 \mathrm{~mL}$ conical flask, and the free acid was neutralised with $1 \mathrm{~N} \mathrm{NaOH}$ solution.0.01 M EDTA solution $(20.00 \mathrm{~mL})$ was transferred quantitatively into the flask using a burette. Sodium acetate buffer solution $(20 \mathrm{~mL})$ of $\mathrm{pH} \sim 5$ was added. The solution was boiled gently on a hot plate for 5 min to speed up the formation of the Al-EDTA 
complex. Xylenol orange indicator (10 drops) was added and mixed well. The solution appeared lemon yellow in colour. If the EDTA is insufficient to chelate all of the aluminium ions, the solution will be deep red in colour. In the latter case, additional EDTA solution (5.00 $\mathrm{mL}$ or more) was added to this deep red solution. It was boiled again until the colour changed to lemon yellow. The solution was then back-titrated with a standardized zinc solution $(0.01 \mathrm{M})$ until the colour changed from lemon yellow to orange red at the endpoint.

Calculation: $\% T A C=67.45 \times \frac{N}{W}\left(V_{b}-V_{s}\right)$

where: $V_{b}$ is blank burette reading without sample solution; $V s$ - burette reading with sample; $N$ - normality of $\mathrm{ZnSO}_{4}$ solution; $\mathrm{W}$ - weight of the sample, $\mathrm{g}$.

\section{Results and Discussion}

\subsection{Preparation of NAP}

The preparation of nanopowders via the thermal plasma route is one of the techniques used for large scale production of nanomaterials because of the high enthalpy, high reaction temperature and steep temperature gradients associated with thermal plasma. It follows a gas phase condensation mechanism.

To optimize the process for the preparation of NAP, various experiments were performed to study the effects of changing process parameters, such as plasma power, reactor pressure and different dilutions of $\mathrm{H}_{2}$ gas in the Ar plasma etc.

\subsubsection{NAP prepared under different plasma power conditions}

The effect of plasma power was studied and it was observed that an increase in power led to a higher vaporization rate, resulting in a better yield without much change in particle size. Figure 2 shows the SEM images of the NAP prepared under different plasma power conditions (18 and $25 \mathrm{~kW}$ ) while keeping the other parameters, such as the flow rates of the quench gas and the plasma gas composition constant. From the SEM images, it was observed that the particles were spherical and mono-dispersed, with a few larger agglomerates. These images reveal that the particles are less than $200 \mathrm{~nm}$ in size. 


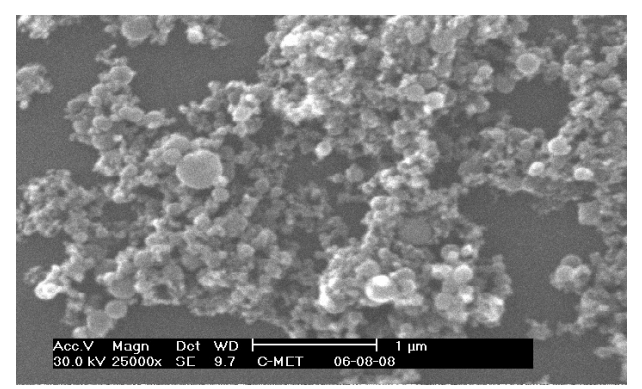

(a)

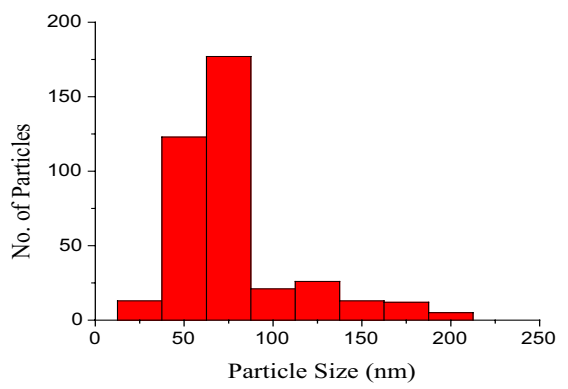

(b)

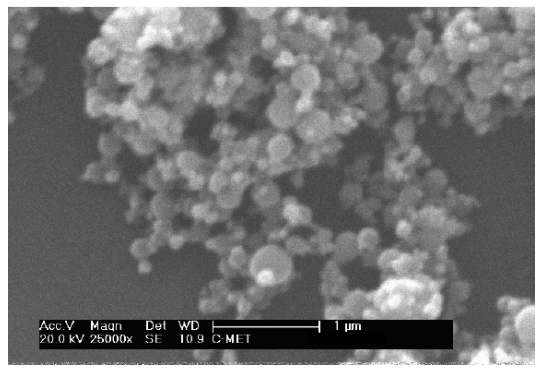

(c)

Figure 2. SEM images of NAP samples prepared at different plasma powers: (a) $18 \mathrm{~kW}$, (b) particle size distribution at $18 \mathrm{~kW}$, (c) $25 \mathrm{~kW}$.

The 2D AFM images (Figure $3 \mathrm{a}$ and $3 \mathrm{~b}$ ) of the Al powders synthesized under 18 and $25 \mathrm{~kW}$ plasma power conditions also confirm that the loosely bound spherical particles were less than $200 \mathrm{~nm}$ in size.

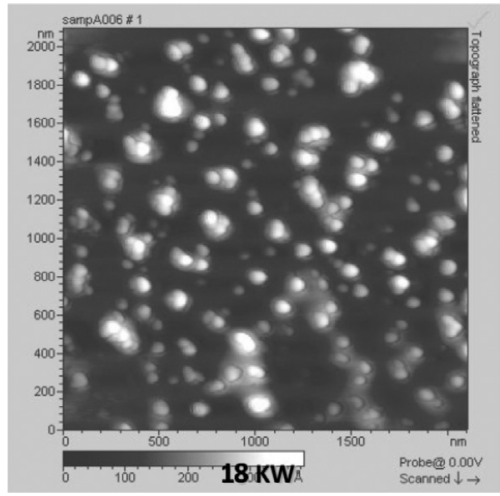

(a)

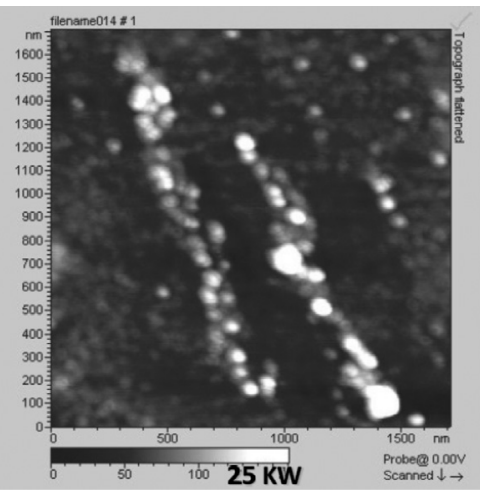

(b)

Figure 3. AFM images of NAP samples prepared at 14 psia and different plasma powers: (a) $18 \mathrm{~kW}$, (b) $25 \mathrm{~kW}$. 


\subsubsection{NAP prepared under different reactor pressures}

In order to increase the production rate, the nanopowders were prepared under different reactor pressure conditions (14.5-10.0 psia) while keeping the power and the flow rates of the different gases constant (plasma power $25 \mathrm{~kW}$ and plasma gas flow rate $35 \mathrm{lpm}$ ). It was observed that a decrease in the reactor pressure resulted in an increase in mean free path, which results in the synthesis of well dispersed and less agglomerated particles. The SEM images (Figure 4) revealed that the particles were spherical with a few larger agglomerates, having particles less than $200 \mathrm{~nm}$ in size.

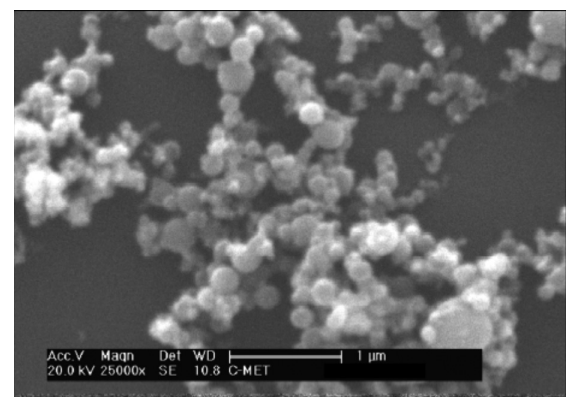

(a)

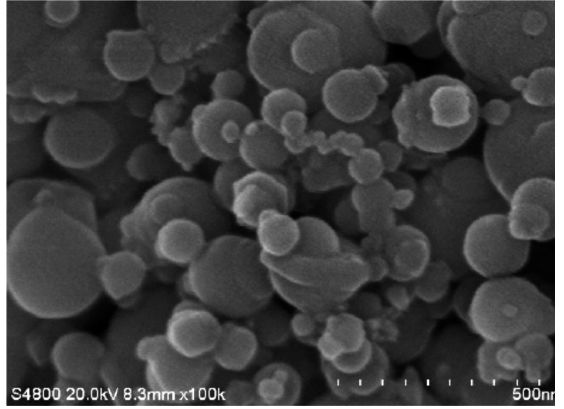

(b)

Figure 4. Typical SEM images of NAP samples prepared at: (a) 10.0 psia, and (b) 14.5 psia, reactor pressure conditions.

\subsubsection{NAP prepared at different $\mathrm{H}_{2}$ dilutions}

To examine the effect of the plasma characteristics on the preparation of NAP, the plasma gas (argon) was diluted using different amounts of hydrogen $(0-20 \%)$ gas, while keeping the total flow (35 lpm) of the plasma gas constant.

Hydrogen is a diatomic gas and $\mathrm{H}_{2}$ plasma has a higher energy content at a given temperature than monoatomic gases like Ar or He, because of the energy associated with the dissociation of the molecules. It has been reported that $\mathrm{H}_{2}$ lowers the boiling point of the material and provides much better heat transfer properties to the plasma [41]. Hydrogen addition increases both the thermal conductivity and the enthalpy of the gas.

Figure 5 shows the SEM images of the NAP prepared under different $\mathrm{H}_{2}$ dilution conditions. The SEM images show spherical particles, however it was observed that with an increase in $\mathrm{H}_{2}$ concentration, the particle size was increased. This is attributed to the difference in vaporization rate due to the hydrogen addition in the arc, leading to a higher vapour concentration and resulting in larger diameters of the nanoparticles [42, 43] 


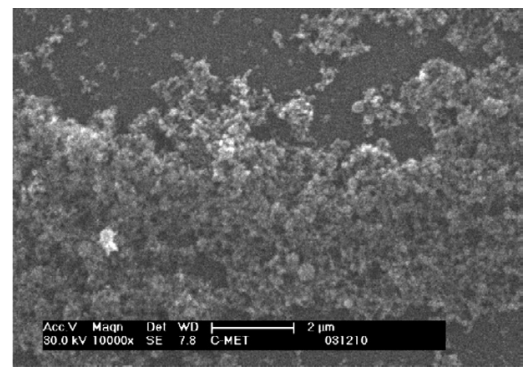

(a)

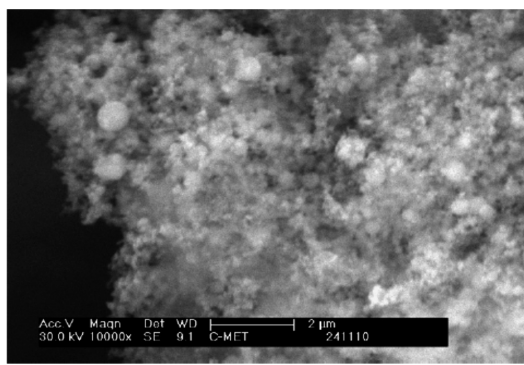

(b)

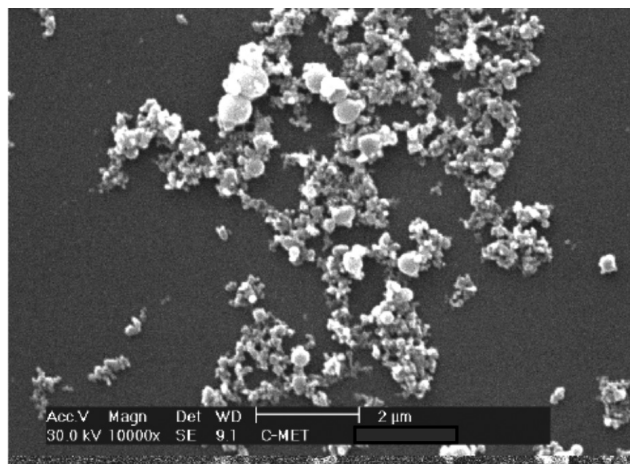

(c)

Figure 5. SEM images of NAP samples prepared at different $\mathrm{H}_{2}$ dilutions: (a) $90 \% \mathrm{Ar}+10 \% \mathrm{H}_{2}$, (b) $80 \% \mathrm{Ar}+20 \% \mathrm{H}_{2}$, (c) $100 \% \mathrm{Ar}$.

The 2D AFM images (Figure 6) of the NAP prepared under different plasma compositions also confirm the increase in the particle size. However, the particles are $<200 \mathrm{~nm}$ at $20 \% \mathrm{H}_{2}$ dilution. No remarkable increase in the yield of NAP was observed by changing the $\mathrm{H}_{2}$ dilution. 


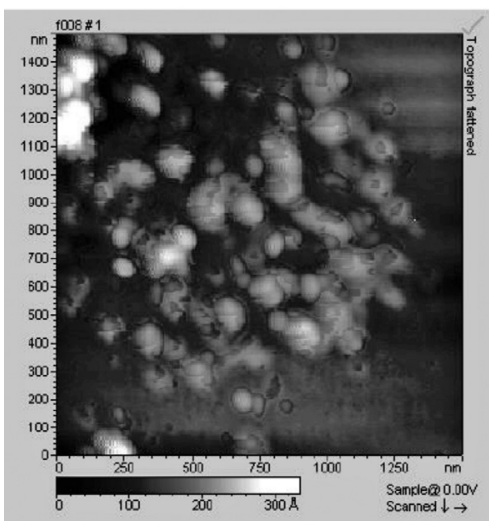

(a)

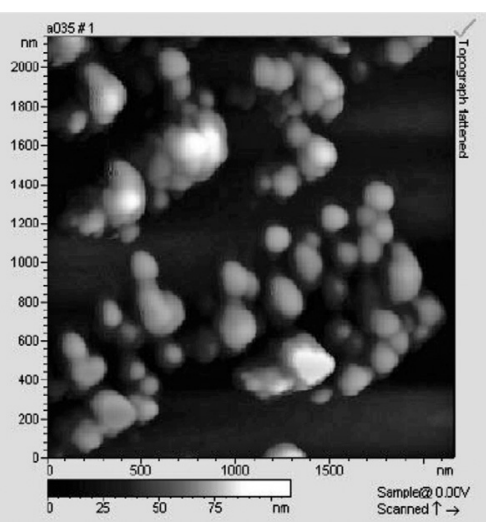

(b)

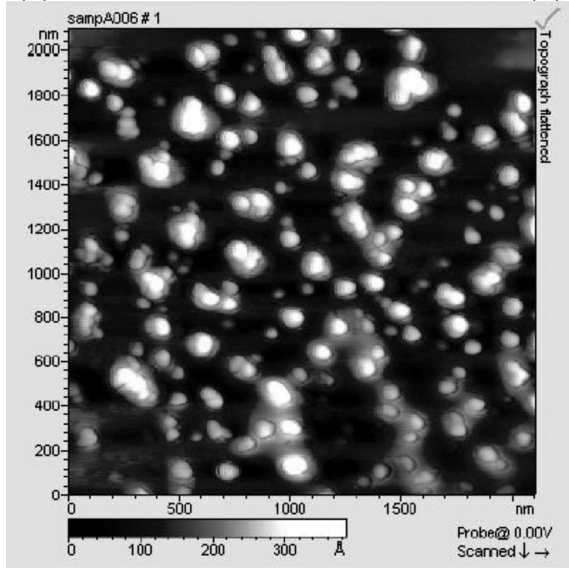

(c)

Figure 6. AFM images of the NAP samples prepared at different $\mathrm{H}_{2}$ dilutions: (a) $90 \% \mathrm{Ar}+10 \% \mathrm{H}_{2}$, (b) $80 \% \mathrm{Ar}+20 \% \mathrm{H}_{2}$, (c) $100 \% \mathrm{Ar}$.

\subsection{Experiments under the optimized process conditions}

By optimizing the chamber pressure, plasma power and plasma gas composition, NAP samples were synthesized at a production rate of $>50 \mathrm{~g} / \mathrm{h}$. The optimised process parameters for the preparation of NAP in the TAPR are given in Table 1. 
Table 1. Optimised process conditions in the TAPR for the preparation of NAP

\begin{tabular}{|c|c|c|}
\hline Sl. No. & Reaction parameter & Optimised condition \\
\hline 1 & Chamber pressure & $14.5 \mathrm{psi}$ \\
\hline 2 & Arc current & $350 \mathrm{~A}$ \\
\hline 3 & Power & $22 \mathrm{~kW}$ \\
\hline 4 & Plasma gas composition & $\operatorname{Ar}(90-100 \%), \mathrm{H}_{2}(0-10 \%)$ \\
\hline 5 & Quench gas & Argon \\
\hline
\end{tabular}

\subsubsection{Characterization}

\section{Estimation of the Active Aluminium Content (AAC)}

Pure NAP is very reactive with oxygen and thus becomes pyrophoric. It is stabilised by controlled surface oxidation with a limited exposure to oxygen, which produce an $\mathrm{Al}_{2} \mathrm{O}_{3}$ layer on the outer surface $(2-6 \mathrm{~nm})$. This oxide layer generally does not contribute constructively for its use as a fuel, and hence it is usually considered as "dead weight". Aluminium metal in the particle core is in the zero oxidation state, and is considered as active aluminium, the effective fuel for HEM applications. Apart from the oxide layer, there may be other impurities, such as nitrogen (in the form of AlN), carbon, and other metals depending upon the preparation methodology and the purity of the starting material employed in the plasma system. The presence of all of these foreign impurities certainly reduces the total aluminium content (TAC) in the bulk NAP. Thus, it affects the performance of the NAP as a fuel in HEM applications. Hence, it is essential to quantify both the AAC and the TAC in the NAP. In view of the above necessity, analytical methods were developed for the estimation of AAC and TAC.

Four methods have been reported in the literature [44-48] for the estimation of AAC in nano aluminium powder. Glotov et al. [47] reported a permanganatometric and volumetric method for the determination of the free aluminium. However, the main disadvantage of this method is the requirement of special equipment for the measurement of the evolved gas and its sensitivity to ambient conditions. Another method by which the active aluminium content can be determined is a thermogravimetric (TG) method [48]. The main drawback of this method is incomplete oxidation of the aluminium powder, which leads to an underestimated result. An indirect estimation method using XRD, BET and HRTEM has also been reported in the literature. All of the above methods were successfully used for the determination of the Al content in conventional micron sized Al particles. However, NAP gave unsatisfactory results because of its high reactivity. 
Fedotova et al. [46] reported a redox titration method for the estimation of AAC. Cerium(IV) sulfate(VI) is a powerful oxidising agent (reduction potential in 1-4M sulfuric acid is 1.44-1.42 V). When an accurately weighed sample of the aluminium powder is added to an excess of a known amount of cerium sulfate solution at slightly elevated temperature, aluminium becomes oxidised to $\mathrm{Al}^{3+}$ ions. The amount of $\mathrm{Ce}^{4+}$ ions remaining is determined by back titration against standardised Mohr's salt (ferrous ammonium sulfate hexahydrate) solution using ferroin indicator (endpoint colour change from yellow to orange). The reaction between $\mathrm{Al}$ and cerium sulfate is shown in Scheme 1, whilst the reaction between cerium sulfate and Mohr's salt is shown in Scheme 2. The same method was adopted here for the estimation of AAC, however the heating time for the dissolution of the $\mathrm{Al}$ in cerium sulfate was increased to $30 \mathrm{~min}$ in order to completely dissolve the aluminium powder.

$$
\begin{aligned}
& \mathrm{Al}+3 \mathrm{Ce}^{4+} \longrightarrow \mathrm{Al}^{3+}+3 \mathrm{Ce}^{3+}-(\text { Scheme } 1) \\
& \mathrm{Fe}^{2+}+\mathrm{Ce}^{4+} \longrightarrow \mathrm{Fe}^{3+}+\mathrm{Ce}^{3+}-(\text { Scheme } 2)
\end{aligned}
$$

\section{Estimation of Total Aluminium Content (TAC)}

Two methods have been reported in the literature $[49,50]$ for the estimation of TAC for micron sized aluminium powder. These are complexometric and gravimetric. The complexometric titration method was adopted here due to the ease of analysis and also to realize better accuracy and precision.

NAP was dissolved in concentrated $\mathrm{HCl}$ to convert all of the aluminium into $\mathrm{Al}^{3+}$. The solution was then diluted to a known volume to prepare a stock sample solution. All of the $\mathrm{Al}^{3+}$ ions present in a known volume of the stock solution were converted to a stable Al-EDTA complex with a known amount of excess EDTA solution. The excess EDTA was back titrated with standard zinc sulfate solution using xylenol orange indicator.

Micron sized, bulk aluminium powder (99.8\% purity) was taken as a standard sample and used to validate the method. The results are shown in Table 2. ALEX (imported from Russia) and TAPR synthesized samples had AAC values of $86 \%$, whereas RFIPR and DCAPR synthesized samples had lower AAC values (70$75 \%$ ). The differences in AAC values may be due to the addition of a higher content of oxygen gas for a longer period of time. The NAP obtained here was greyish in colour, with a bulk density of $\sim 0.29-0.32 \mathrm{~g} / \mathrm{cm}^{3}$ (Table 3), which is much lower than that of micron aluminium. 
Table 2. AAC and TAC values of different NAP samples

\begin{tabular}{|c|c|c|c|c|}
\hline NAP Sample & $\begin{array}{c}\text { AAC } \\
{[\%]}\end{array}$ & $\begin{array}{c}\text { STDEV } \\
\sigma\end{array}$ & $\begin{array}{c}\text { TAC } \\
{[\%]}\end{array}$ & $\begin{array}{c}\text { STDEV } \\
\sigma\end{array}$ \\
\hline EEW, (ALEX, Russia) & 85.5 & 0.66 & 96.3 & 0.4 \\
\hline DCAPR, (UOP) & 70.0 & 0.56 & 85.0 & 0.7 \\
\hline TAPR, (C-MET) & 86.9 & 0.32 & 92.0 & 0.34 \\
\hline RFIPR, (ARCI) & 75.6 & 0.49 & 85.6 & 0.26 \\
\hline $\begin{array}{c}\text { Micron-Aluminium } \\
\text { powder, (HEMRL) }\end{array}$ & 98.7 & 0.33 & 100.8 & 0.71 \\
\hline
\end{tabular}

\subsection{XRD and TEM analysis}

Typical XRD scans of NAP prepared by different routes are shown in Figure 7. The X-ray diffraction pattern of all samples exhibited the characteristic peaks of nano aluminium. The diffraction pattern of NAPs prepared by different methods closely matches with micron Al. However, careful observation further showed that the Micron Al shows no impurity peaks, whereas ALEX powder, TAPR and RFIPR samples showed minor $\mathrm{AlN}, \mathrm{Al}_{2} \mathrm{O}_{3}$ and $\mathrm{Al}(\mathrm{OH})_{3}$ peaks, respectively.

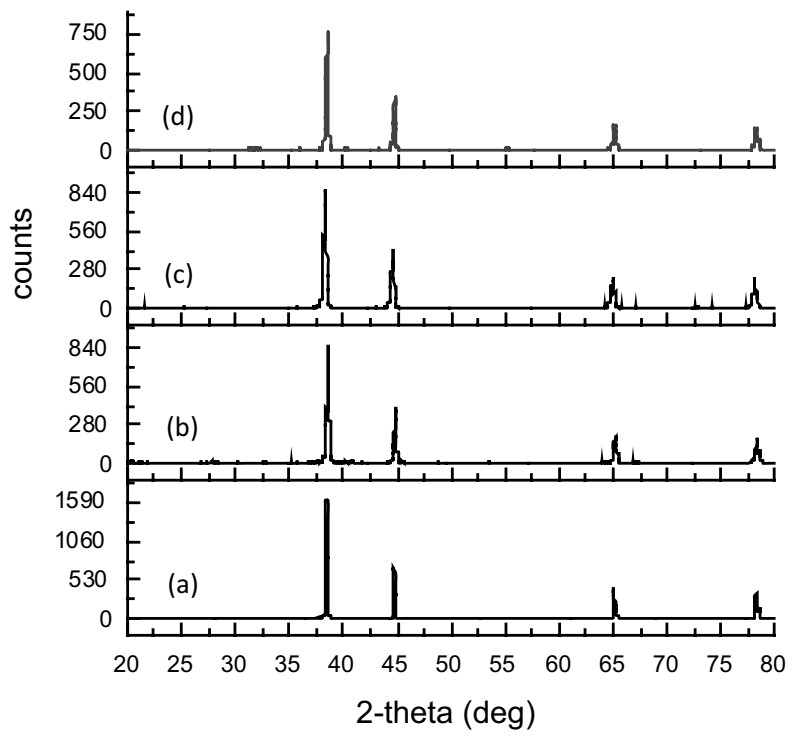

Figure 7. XRD scans of NAP samples prepared by different routes: (a) MicronAl, (b) TAPR,(c) EEW, (d) RFIPR. 


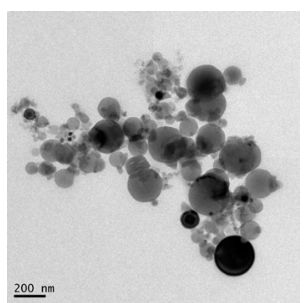

(a)

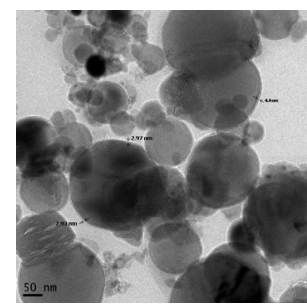

(b)

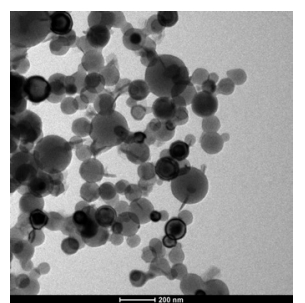

(c)

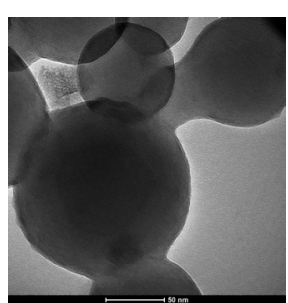

(d)

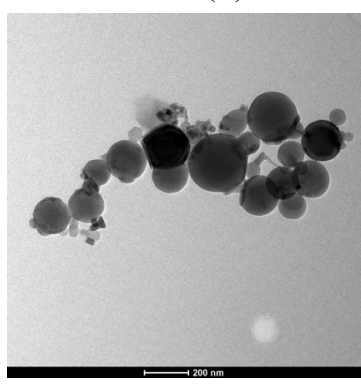

(e)

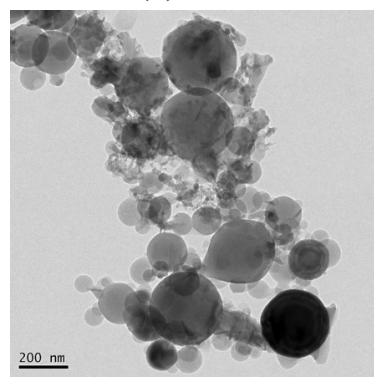

(f)

Figure 8. HRTEM images of NAP samples prepared by different routes: (a) and (b) TAPR; (c) and (d) EEW (ALEX); (e) DCAPR; (f) RFIPR.

A comparison of the HRTEM micrographs is shown in Figure 8. The HRTEM images indicate that the particles are mostly spherical in shape. The average particle size is given in Table 3. It was quite interesting to see the differences in average particle size obtained with different plasma systems. ALEX and DCAPR samples showed comparatively narrow particle size distributions compared to the TAPR and RFIPR samples, which showed broader particle size distributions. Figure $8 \mathrm{~b}$ represents the HRTEM of an NAP sample prepared via TAPR, which showed a thin layer of alumina as a passivating layer of thickness around 3-5 $\mathrm{nm}$. Wider particle size distributions might be the reason for the higher AACs in TAPR samples. A closer study of Figure 8d reveals that in ALEX powder, the particles contact each other through their outer oxide layers, which indicates that clustering of the particles may have occurred after the oxidation of the metallic cores [51]. 
Table 3. BD, BET surface area and particle size of NAP samples

\begin{tabular}{|c|c|c|c|c|}
\hline \multirow{2}{*}{ NAP sample } & \multirow{3}{*}{$\begin{array}{c}\mathrm{BD} \\
{\left[\mathrm{g} / \mathrm{cm}^{3}\right]}\end{array}$} & $\begin{array}{c}\text { BET SA } \\
{\left[\mathrm{m}^{2} / \mathrm{g}\right]}\end{array}$ & \multicolumn{2}{|c|}{ Particle size, [nm] } \\
\cline { 4 - 5 } & 0.27 & 21 & 102 & $100-200$ \\
\hline EEW, (ALEX, Russia) & 0.3 & 19.3 & 114 & $100-250$ \\
\hline DCAPR, (UOP) & 0.3 & 12.4 & 178 & $50-250$ \\
\hline TAPR, (C-MET) & 0.29 & 11.5 & 193 & $50-300$ \\
\hline RFIPR, (ARCI) & 0.32 & 0.38 & 5060 & - \\
\hline $\begin{array}{c}\text { Micron-Aluminium } \\
\text { powder, (HEMRL) }\end{array}$ & 1.5 & & \multicolumn{2}{|c}{} \\
\hline
\end{tabular}

\subsection{Surface area analysis}

Surface area measurements are widely used to provide a measure of the average particle size of NAPs. Typically, the particle size calculation is based on the assumption that particles are closed spheres with uniform surfaces and uniform sizes.

The specific surface results obtained from gas adsorption, along with the average particle size $\left(\mathrm{A}_{\mathrm{s}}\right)$ calculated using Equation 1, are listed in Table 3.

$$
\mathrm{A}_{\mathrm{s}}=6000 /(\mathrm{SA} \times \mathrm{d})
$$

where: SA - surface area of NAP samples, $\mathrm{m}^{2} / \mathrm{g} ; \mathrm{d}$ - density of aluminium $\left(2.7 \mathrm{~g} / \mathrm{cm}^{3}\right)$.

The results are summarised in Table 3. The BET surface areas of the NAP samples were $11-19 \mathrm{~m}^{2} / \mathrm{g}$ which is similar to the ALEX sample value. It was further observed that the BET average particle sizes are within the size range obtained by HRTEM.

\section{Conclusions}

A gas phase condensation method has been developed for the preparation of NAP at $50 \mathrm{~g} / \mathrm{h}$ using TAPR. The influence of process parameters such as plasma power, chamber pressure and plasma gas composition have been studied and optimized to realize NAP with particle sizes in the range of 50-250 nm with high AAC values. It was observed that an increase in power lead to a higher yield and a decrease in reactor pressure resulted in less agglomerated particles. The effect of hydrogen dilution was also studied. It was observed that higher concentrations of hydrogen gas in the plasma gas composition resulted in an increase in particle size. Thus, we have been able to control the NAP growth by 
plasma evaporation by controlling the reactor parameters. Isolated NAP samples were characterized for purity analysis (AAC and TAC), BD, BET surface area, XRD and TEM. The results have been compared with those prepared using other thermal plasma reactors (DCAPR and RFITPR) and the EEW technique. It was observed that the particle size distribution is broad in NAP samples prepared by TAPR in comparison to ALEX powder.

\section{Acknowledgement}

Authors acknowledge the guidance and encouragement given by Shri B. Bhattacharya, Outstanding Scientist and Director, HEMRL, to carry out this research work. The authors also acknowledge the support rendered by Dr. D. P. Amalnerkar, Director, C-MET, for conducting experiments in the TAPR. We are also thankful to the University of Pune and ARCI, Hyderabad, for providing samples prepared by DCAPR and RFIPR respectively. Support extended by the Pyro Division of HEMRL (for XRD) and the National Chemical Laboratory (NCL), Pune (for HRTEM), is also acknowledged.

\section{References}

[1] De Luca L.T., Galfetti L., Severini F., Meda L., Marra G., Vorozhtsov A.B., Sedoi V.S., Babuk V.A., Burning of Nano-aluminized Composite Rocket Propellants, Combustion, Explosion, and Shock Waves (Engl. Transl.), 2005, 41, 680-692.

[2] Sundaram D.S., Yang V., Zarko V.E., Combustion of nano aluminium particles (Review), Combustion, Explosion, and Shock Waves (Engl. Transl.), 2015, 51(2), 173-196.

[3] Ivanov Y.F., Osmonoliev M.N., Sedoi V.S., Arkhipov V.A., Bondarchuk S.S., Vorozhtsov A.B., Korotkikh A.G., Kuznetsov V.T., Productions of Ultra-fine Powders and Their Use in High Energetic Compositions, Propellants Explos. Pyrotech., 2003, 28, 319-333.

[4] Mench M.M., Yeh C.L., Kuo K.K., Propellant Burning Rate Enhancement and Thermal Behavior of Ultra-fine Aluminium Powder (ALEX), $29^{\text {th }}$ Int. Annu. Conf. ICT: Energetic Materials, Production, Processing and Characterisation, Karlsruhe, Germany, 1998, 30, (1-15).

[5] Simonenko V.N., Zarko V.E., Comparative Studying and the Combustion Behaviour of Composite Propellants Containing Ultrafine Aluminium, $30^{\text {th }}$ Int. Annu Conf. ICT: Energetic Materials: Modelling of Phenomena, Experimental Characterization, Environmental Engineering, Karlsruhe, Germany, 1999, 21/1.

[6] Mench M.M., Kuo K.K., Yeh C.L., Lu Y.C., Comparison of Thermal Behaviour of Regular and Ultra-fine Aluminium Powders (Alex) Made from Plasma Explosion 
Process, Comb. Sci. Technol., 1998, 135, 269-292.

[7] Meziani M.J., Bunker C.E., Lu F., Li H., Wang W., Guliants E.A., Quinn R.A., Sun Y.P., Formation and Properties of Stabilised Aluminium Nanoparticles, ACS Appl. Mater. Interfaces, 2009, 1(3), 703-709.

[8] Ivanov Y.F., Osmonoliev M.N., Sedoi V.S., Arhipov V.A., Bondarchuk S.S., Vorozhtsov A.B., Korotkikh A.G., Kuznetsov V.T., Production of Ultra-fine Powders and Their Use in High Energetic Compositions, Propellants Explos. Pyrotech., 2003, 28(6), 319-333.

[9] Dreizin E.L., Metal-based Reactive Nanomaterials, Progress in Energy and Combustion Science, 2009, 35, 141-167.

[10] Lessard P., Beaupre F., Brousseau P., Burn Rate Studies of Composite Propellants Containing Ultrafine Metals, $32^{\text {nd }}$ Int. Annu. Conf. ICT, Karlsruhe, Germany, 2001, 88 .

[11] Piercey D.G., Klapötke T.M., Nanoscale Aluminum - Metal Oxide (Thermite) Reactions for Application in Energetic Materials, Cent. Eur. J. Energ. Mater, 2010, 7(2), 115-129.

[12] Firooz A., A New Approach to Understanding the Mechanism and Effect of Phase Change of Aluminum in Aluminum Nanoparticles Oxidation: An Experimental Study, International Journal of Scientific \& Engineering Research, 2014, 5(9), 384-388.

[13] Puszynski J.A., Formation, Characterization and Reactivity of Nanoenergetic Powders, 29th Int. Pyrotechnic Conf., Colorado, USA, 2002, 191.

[14] Gen M.Y., Ziskin M.S., Petrov Y.I., Study of Size Distribution of Al Aerosol in Dependence of Operational Conditions (in Russian), Doklady AN SSSR, 1959, 127 , 366-368.

[15] Gen M.Y., Miller A., A Method of Obtaining Metal Aerosols (in Russian), USSR Inventors, Certificate No. 814432, Bulletin of Invention, 1981, (11), 25.

[16] Groza J.R., Sintering of Nanocrystalline Powders, Int. J. Powder Metallurgy, 1999, 35(7), 59-66.

[17] Hull M., Tetronics: Plasma Processing Holds Key to Consistent Nanopowders, Powder Metall., 2002, 45(1), 8-9.

[18] Paskalov G., Plasma Processing of Aluminium Nano-fuel; http://www.ispcconference.org/ispcproc/ispc20/3.pdf

[19] Settumba N., Garrick S.C., Modeling and Simulation of Nano-aluminium Synthesis in a Plasma Reactor, in: Advancement in Energetic Materials and Chemical Propulsion, Begell House Inc., (K.K. Kuo, J.D. Rivera, Eds.), 2007, pp. 643-655, ISBN 978-1-56700-239-3.

[20] Jiayin G., Xiaobao F., Dolbec R., Siwen X., Jurewicz J., Boulos M., Development of Nanopowder Synthesis Using Induction Plasma, Plasma Sci. Technol., 2010, $12(2), 188$.

[21] Kearns M., Development and Applications of Ultrafine Aluminium Powders, Mater. Sci. Eng. A, 2004, 375-377, 120-126.

[22] Seo J.-HO and Hong B.-G., Thermal Plasma Synthesis of Nano-Sized Powders, 
Nuclear Engineering and Technology, 2012, 44(1), 9-20.

[23] Yamamoto N., Nishiyama T., Nagayama K., Process Controlled Synthesis of Aluminum Nanoparticles as a Next Generation Propellant; http://www.aero. kyushu-u.ac.jp/aml/laser/Al\%20nano.pdf

[24] Schroder K.A., Jackson D.K., Radial Pulse Arc Discharge Gun for Synthesizing Nanopowders, Patent US 2005/0000950 A1, Jan 2005.

[25] Yanik B. Agustos H., Ipek Y., Koyun A., Uzunsoy D., Synthesis and Characterization of Aluminium Nanoparticles by Electric Arc Technique, Arab J. Sci. Eng, 2013, 38, 3587-3592.

[26] Faraji M., Poursalehi R., Fkhazraei A., The Effect Of Surfactant on Colloidal Stability, Oxidation and Optical Properties of Aluminium Nanoparticles via DC Arc Discharge in Water, Procedia Materials Science, 2015, 11, 684-688.

[27] Zelinskii V.Y., Yavorovskii N.A., Proskurovskaya L.T., Davydovich V.I., Structural State of Aluminium Particles Prepared by Electric Explosion (in Russian), Fizika i Khimiya Obrabotki Materialov, 1984, 1, 57-59.

[28] Kwon Y.-S., Jung, J,-H., Yavorovsky N.A., Illyn A.P., Kim, J.-S., Ultrafine Powder by Wire Explosion Method, Scr. Mater, 2001, 44(8), 2247-2251.

[29] Sarathi R., Sindhu T.K., Chakravarthy S.R., Generation of Nano Aluminium Powder Through Wire Explosion Process and its Characterisation, Mater. Char., 2007, 58, 148-155.

[30] Tepper F., Nanosize Powders Produced by Electro-explosion of Wire and Their Potential Applications, Powder Metall., 2000, 43(4), 320-322.

[31] Li H., Meziani M.J., Lu F., Bunker C.E., Guliants E.A., Sun Ya-P., Templated Synthesis of Aluminium Nanoparticles-A New Route to Stable Energetic Materials, J. Phys. Chem. C, 2009, 113(48), 20539-20542.

[32] Chung S.W., Guliants E.A., Bunker C.E., Hammerstroem D.W., Deng Y., Burgers M.A., Jelliss P.A., Buckner S.W., Capping and Passivation of Aluminium Nanoparticles Using Alkyl Substituted Epoxides, Langmuir, 2009, 25(16), 88838887.

[33] Foley T.J., Johnson C.E., Higa K.T. Inhibitions of Oxide Formation on Aluminium Nanoparticles by Transition Metal Coating, Chem. Mater., 2005, 17, 4086-4091.

[34] Haber J.A., Buhro W.E., Kinetic Instability of Nanocrystalline Aluminium Prepared by Chemical Synthesis; Facile Room-temperature Grain Growth, J. Am. Chem. Soc., 1998, 120, 10847-10855

[35] Jouet R.J., Warren A.D., Rosenberg D.M., Bellitto V.J., Park K., Zachariah M.R., Surface Passivation of Bare Aluminium Nanoparticles Using Perfluoroalkyl Carboxylic Acids, Chem. Mater., 2005, 17(11), 2987-2996.

[36] Ghanta S.R., Muralidharan K., Chemical Synthesis of Aluminium Nanoparticles, J. Nanopart. Res., 2013, 15, 1715.

[37] Gottapu S., Padhi S.K., Krishna M.G., Muralidharan K., Poly(vinylpyrrolidone) Stabilized Aluminium Nanoparticles Obtained by the Reaction of $\mathrm{SiCl}_{4}$ with $\mathrm{LiAlH}_{4}$, New J. Chem. 2015, 39, 5203-5207.

[38] Lui Y., Zhao S., Tao D., Liang Z., Huang D., Xu Z., Synthesis of Size Controlled 
and Discrete Core Shell Aluminium Nanopaticles with a Wet Chemical Process, Mater. Lett., 2014, 121, 54-57.

[39] Eom N., Bhuiyan M.H., KimT.-S., HongS.-J., Synthesis and Characterization of Agglomerated Coarse Al Powders Comprising Nanoparticles by Low Energy Ball Milling Process, Mater. Trans., 2011, 52(8), 1674-1678.

[40] Abdoli H., Ghanbari M., Baghshahi S., Thermal Stability of Nanostructured Aluminum Powder Synthesized by High-energy Milling, Mater. Sci. Eng. A, 2011, 528, 6702-6707.

[41] Eckert J., Holzer J.C. Ahn C.C., Fu Z., Johnson W.L. Melting Behaviour of Nanocrystalline Aluminium Powders, Nanostruct. Mater., 1993, 2, 407-413

[42] Munz R.J., Addona T., Cruz A.-C. D., Application of Transferred Arcs to the Production of Nanoparticles, Pure Appl. Chem., 1999, 71, 1889-1897.

[43] Watanabe T., Tanaka M., Thermal Plasma Processing for Functional Nanoparticle Synthesis, Proc. $16^{\text {th }}$ ASEAN Regional Symposium on Chemical Engineering, Manila, Philippines, 2009, 47.

[44] Fedotova T.D., Malahov V., Glotov O.G., Kiryanova A., Permanganatometric Determination of Metallic Aluminum in Condensed Combustion Products, Sibirskii Khimicheskii Zhurnal, 1992, 2, 37.

[45] Glotov O.G., Zyryanov V.Y., The Effect of Pressure on Characteristics of Condensed Combustion Products of Aluminized Solid Propellant, Archivum Combustionis, 1991, 11, (3/4), 251.

[46] Fedotova T.D., Glotov O.G., Zarko V.E., Application of Cerimetric Methods for Determining the Metallic Aluminum Content in Ultrafine Aluminum Powders, Propellants Explos. Pyrotech., 2007, 32, 160-164.

[47] Fedotova T.D., Glotov O.G., Zarko V.E., Chemical Analysis of Aluminum as Propellant Ingredient and Determination of Aluminum and Aluminum Nitride in Condensed Combustion Products, Propellants Explos. Pyrotech., 2000, 25, 325 332.

[48] Chen L., Song W., Lv J., Chen X., Xie C., Research on the Methods to Determine Metallic Aluminum Content in Aluminum Nanoparticles, Mater. Chem. Phys., 2010, 120, 670-675.

[49] Bassett J., Denney R.C., Jeffery G.H., Mendham J., Vogel's Textbook of Quantitative Inorganic Analysis, $4^{\text {th }}$ ed., ELBS and Longman, London, 1979.

[50] Yang S.-P., Tsai R.-Y., Complexometric Titration of Aluminum and Magnesium Ions in Commercial Antacids. An Experiment for General and Analytical Chemistry Laboratories, J. Chem. Edu., 2006, 83(6), 906.

[51] Kwok Q.S.M., Badeen C., Armstrong K., Turcotte R., Jones D.E.G., Gertsman V.Y., Hazard Characterization of Uncoated and Coated Aluminium Nanopowder Compositions, J. Propul. Power, 2007, 23, 659-682. 
